\title{
La Gestión Del Agua Como Bien Común EN El Municipio De Cochabamba (Bolivia). A 19 AÑos De La Guerra Del AguA ${ }^{1}$
}

\section{Anna Ramoneda Martí}

Resumen: La siguiente investigación es el resultado de un estudio sobre la gestión del agua en el municipio de Cochabamba (Bolivia), a 19 años de la Guerra del Agua. En concreto, se analiza si tal movimiento social sirvió para reavivar la idea de gestionar el agua bajo los principios de bien común, a la vez que se expone cómo ha ido evolucionando esta gestión y cuáles son los retos actuales. Los resultados apuntan a un resurgimiento de la idea de agua gestionada como bien común durante la Guerra del Agua, la cual se va perdiendo con el tiempo hasta llegar a desaparecer por completo en el momento actual. En gran medida, la razón por la que se diluye resulta de una pérdida de influencia por parte de los movimientos sociales y sociedad civil frente a los órganos de toma de decisión formales.

Palabras clave: Agua, bienes comunes, género, desigualdades, Bolivia, Cochabamba.

\footnotetext{
${ }^{1}$ Esta investigación es el resultado de un trabajo de final de grado de los estudios de Sociología, realizados en la Universitat de Barcelona (UB). La investigación y el desarrollo de esta se llevaron a cabo entre enero y septiembre del año 2019.
} 
Resum: La investigació que aquí presentem és el resultat d'un estudi sobre la gestió de l'aigua al municipi de Cochabamba (Bolívia), a 19 anys de la Guerra de l'Aigua. En concret, s'hi analitza si tal moviment social va servir per revifar la idea de gestionar l'aigua sota els principis del bé comú, a la vegada que s'explica com ha anat evolucionant tal gestió i es mencionen els reptes actuals. Els resultats apunten a un ressorgiment de la idea d'aigua gestionada com a bé comú durant la Guerra de l'Aigua però que es va perdent a mesura que avança el temps, arribant a desaparèixer quasi completament en les premisses de la gestió actual. La raó primordial per la qual es dilueix rau a la pèrdua d'influència dels moviments socials i la societat civil front els òrgans de presa de decisions formals.

Paraules clau: Aigua, bens comuns, gènere, desigualtats, Bolívia, Cochabamba.

Summary: The following research is the result of a study on water management in the municipality of Cochabamba (Bolivia) 19 years after the Water War. In particular, the research analyses whether such a social movement served to revive the idea of managing water under the principles of the commons, while at the same time explaining how this management has evolved and, specifically, what the current challenges are. The results indicate a resurgence of the idea of water managed as a common good during the Water War, which has been lost over time, disappearing completely at the present. The main reason for these results could be a loss of influence of social movements and civil society in the face of formal decision-making institutions.

Keywords: Water, commons, gender, inequalities, Bolivia, Cochabamba

Resum: La investigació aquí present és el resultat d'un estudi sobre la gestió de l'aigua al municipi de Cochabamba (Bolívia), a 19 anys de la Guerra de l'Aigua. En concret s'analitza si tal moviment social va 
servir per a revifar la idea de gestionar l'aigua sota els principis del bé comú, a la vegada que s'explica com ha anat evolucionant tal gestió i es mencionen els reptes actuals. Els resultats apunten a un ressorgiment de la idea d'aigua gestionada com a bé comú durant la Guerra de l'Aigua, però la qual es va perdent a mesura que avança el temps, arribant a desaparèixer quasi completament en les premisses de la gestió actual. La raó primordial per al qual es dilueix, ve donada per la pèrdua d'influència per part dels moviments socials i la societat civil envers als òrgans de presa de decisions formals.

Paraules clau: Aigua, bens comuns, gènere, desigualtats, Bolívia, Cochabamba.

\section{Introducción}

Bolivia es un país situado en la zona centro-occidental de América del Sur. No tiene costa y se encuentra rodeado de Perú por el noroeste, Chile por el suroeste, Argentina por el sur, Paraguay por el sureste y Brasil por su zona este y norte. Su situación social es característica, ya que un $62 \%$ de la población (INE, 2012) se identifica como miembro de alguno de los grupos étnicos originarios; por tanto, el porcentaje de población indígena es notablemente alto. Además, tradicionalmente se ha tratado de uno de los países más pobres del mundo (Galeano, 2013: 51), el cual sufre de una tremenda desigualdad y racismo inherentes que supone, en muchos casos, que exista una relación directa entre formar parte de algún grupo étnico originario y pertenecer a una clase social de estrato bajo (Cabezas, 2007: 191).

Este estudio pretende descifrar la situación actual que presenta una de las ciudades de Bolivia, Cochabamba, por lo que hace a su distribución de agua para consumo humano. Cochabamba es una ciudad situada en Bolivia, en el departamento de nombre homónimo, capital de este y único municipio de la provincia de El Cercado (provincia del departamento de Cochabamba). El nombre Cochabamba proviene de los términos quechua hocha y pampa: valle y laguna/lago. Antiguamente, 
antes de la colonia ${ }^{2}$, el valle de Cochabamba era una zona con mucha agua superficial. Poco a poco, pero, esta agua ha ido desapareciendo, en gran medida, debido a la acción humana (Thompson Hines, 2015). Más recientemente cabe destacar una expansión de El Cercado extremadamente desorganizada: a partir de los años 80 y a lo largo de todo el período neoliberal -del 1985 al 2006 (Villegas, 2010: 19)-, Bolivia vivió una importante relocalización de personas mineras y trabajadoras del campo las cuáles abandonaron las zonas mineras y rurales y se asentaron en las grandes ciudades, debido en gran medida al empeoramiento sus condiciones de trabajo a causa de las privatizaciones, el cierre de numerosas minas por el agotamiento de estas y del cambio en el uso del suelo: el suelo valluno pasó de ser medio de producción a ser mercancía (Linsalata L. , 2014a: 252). El resultado es que Cochabamba pasa de tener alrededor de 200000 habitantes en 1976 a quintuplicar su población en poco más de 30 años (Linsalata L., 2014a: 251). De esta forma, la ciudad se come al campo sin tener en cuenta aspectos básicos para la renovación del agua subterránea: se cimenta y se construye encima de las zonas de recarga hídrica sin legislaciones que las protejan ni ningún tipo de planificación urbanística: se priman los intereses personales y las ganancias privadas que proporciona el mercado inmobiliario al bienestar presente y futuro de la población (Linsalata L., 2014b).

Cochabamba es, en la actualidad, una ciudad y área metropolitana que ocupa un valle fecundo pero que es, en realidad, una zona semidesértica. Tiene unos 70 días lluviosos al año y la precipitación anual varía de 400 a $500 \mathrm{~mm} /$ año (Ledo, 2013: 15), además, la poca agua que cae regenera cada vez menos los acuíferos ya que estos son impermeabilizados por la expansión del área urbana. El resultado es que el agua en Cochabamba es el principal motivo de generación de desigualdad, por encima de cualquier otro indicativo (Ledo, 2013).

2 Colón llega a América en el año 1492 y en ese momento se empieza la colonización. 
La ciudad de Cochabamba es una muestra clara del crecimiento de dos mundos polares conformados por el agua: mientras que en la zona centro y norte, donde se acumula la mayor cantidad de agua tanto superficial como subterránea, se acomodan las clases medias y altas y se trata de un espacio planificado y con todos los servicios necesarios, el área no planeada y muchas veces sin acceso a los servicios básicos, se encuentra en la periferia sur, donde el agua tanto superficial como subterránea es muy escasa. En esta zona por lo general encontramos a los habitantes de nivel socio-ocupacional más bajo. Estas son las bases que conforman el complejo entramado que dispensa el agua de sus habitantes, el cual se divide entre la empresa municipal SEMAPA 3 , las $\mathrm{OLPES}^{4} \mathrm{y}$, allí donde no llegan ni unos ni otros, los carros cisterna ${ }^{5}$.

3 SEMAPA (Servicio Municipal de Agua Potable y Alcantarillado): Es la empresa municipal de suministro de agua potable y alcantarillado. Fue creada en 1967. En 1999 se entrega en concesión a la empresa privada Aguas del Tunari y en abril de 2000, después de una serie de conflictos sociales, pasa nuevamente a ser atendida por SEMAPA (SEMAPA, 2017). Actualmente se trata de una EPSA (Empresa Pública de Saneamiento y Agua potable) regulada y fiscalizada por el gobierno estatal boliviano (AAPS; MMAyA, 2017). SEMAPA proporciona cobertura de agua potable y alcantarillado al Cercado sin embargo no tiene, ni ha tenido nunca, capacidad para cubrir al 100\% la demanda del líquido en su territorio de abastecimiento.

4 OLPES (Operadores Locales de Pequeña Escala): En las zonas de la ciudad donde no llega la empresa municipal; básicamente en el sur de la ciudad; se han generado diversas alternativas. Una de ellas son las OLPES, gestiones comunitarias de sistemas de agua creados por los mismos habitantes de la zona. Los primeros sistemas comunitarios de agua empiezan a emerger en Cochabamba a principios de los años 90 (Linsalata L. , 2014b: 254), bajo iniciativa de la inmigración que empieza a llegar a la zona a partir de los 80. Estos sistemas, autogestionados por la población beneficiaria, pueden tener distintas formas jurídicas: cooperativas, asociaciones, comités, etc. La forma que adoptan depende de las necesidades de cada zona, a la vez que también de su tamaño. Por lo que hace a la obtención del líquido, según Lucía Linsalata (2014a), en algunos casos se abastecen de agua subterránea a través de pozos, pero en otros casos no tienen acceso a aguas subterráneas y, entonces, se suele optar por construir tanques elevados y comprar el agua de los aguateros en bloque, ya que sale más barato que comprarla individualmente. En el tercer de los casos, el sistema es mixto: entre tanques elevados y pozos. 
La tradicional importancia que tiene el agua en Cochabamba sumado al proceso de neoliberalización del país -el cual se inicia en el año 1985 y se traduce en una privatización masiva de las empresas nacionales y la subordinación de la economía boliviana a las directrices del Banco Mundial y el Fondo Monetario Internacional (Villegas, 2010) - genera, en el año 2000 en Cochabamba, lo que se llamó la Guerra del Agua.

La síntesis de este proceso es como sigue: En 1999, el Banco Mundial propone a las autoridades nacionales y locales la privatización de SEMAPA, la empresa de agua pública de Cochabamba, y el 3 de septiembre del año 1999 se le cede en concesión a un consorcio privado internacional llamado Aguas del Tunari ${ }^{6}$. También se le cede, a Aguas del Tunari, el poder de usufructo exclusivo de la mayoría de fuentes de agua de la zona. El acuerdo incluye, entre otras cosas, la elaboración del Proyecto Múltiple Misicuni (PMM) ${ }^{7}$ por parte del consorcio privado. El resultado de tal acuerdo acaba siendo el traslado del coste total del PMM a la población cochabambina, lo cual se

${ }^{5}$ Carros aguateros o camiones cisterna: Existen zonas donde no llega SEMAPA y tampoco se ha generado ninguna OLPE. En estos casos, están los carros aguateros. Estos son formas de distribución de agua completamente privadas; se trata de personas o grupos de personas particulares que, con sus propios carros cisterna, llevan agua a distintos sitios de la ciudad para venderla a aquellos habitantes que necesiten el líquido.

6 "El consorcio Aguas del Tunari, con registro legal en la Islas Caimán, era la cría peculiar de algunos de los jugadores más importantes en el mundo del negocio de agua: International Water Limited (propiedad de Edison SpA de Italia y Bechtel de EEUU), con 50\%; se juntó con Abengoa, de España (con 25\%), y cuatro inversionistas bolivianos (25\%), unos ligados al proyecto Misicuni, y otros ligados a un partido del Gobierno.” (Kruse \& Vargas, 2000: 3).

7 Proyecto Múltiple Misicuni (PMM): el PMM es un proyecto originalmente concebido, de forma teórica, en los años 40 (Ortiz Jimenez, 2005, p. 6). El PMM propone "la captación de aguas de la cuenca del Río Misicuni en la Cordillera Oriental de los Andes y su conducción hasta el valle central y la ciudad de Cochabamba [es decir, toda el área metropolitana] para consumo humano, riego y generación eléctrica. Contempla ambiciosas y costosas obras de captación y retención de aguas, la perforación de un túnel de 19,5 $\mathrm{km}$ y otros túneles secundarios de aducción, y la instalación de una planta hidroeléctrica" (Kruse, 2005: 21). 
traduce en un incremento de las tarifas del agua para consumo humano de hasta un 300\% (Coordinadora en Defensa del Agua y de la Vida, 2000).

Por lo tanto, son dos las causas directas que provocan el descontento en la población: (1) La concesión, en forma poco clara, de la empresa municipal de distribución de agua -SEMAPA- a un consorcio privado internacional, Aguas del Tunari, incluyendo la implementación del proyecto Misicuni y la consecuente subida de los precios de un líquido básico para la vida y (2) la aprobación en el parlamento de la Ley 2029 de Servicios de Agua Potable y Alcantarillado Sanitario, la cual sigue recomendaciones del Banco Mundial (Crespo, 2000) e indica que se ceden las fuente de agua de la zona a Aguas del Tunari, cosa que supone indignación tanto en las comunidades del sur del Cercado, que tienen agua gracias a sus propios esfuerzos físicos y económicos, y que siempre habían manejado de forma tradicional el agua de riego a través de sus usos y costumbres. Por tanto, la Guerra del Agua surge de un descontento general, se trata de un movimiento en el que participa toda la población, des de las clases medias del centro de la ciudad a las más bajas de las áreas periurbanas y tanto del campo como de la ciudad. Las demandas del movimiento "se condensarían poderosamente en torno a [...] romper el contrato de concesión [con Aguas del Tunari] y la anulación de la Ley 2029, a ser sustituida por otra diseñada por los regantes y otras organizaciones sociales" (Kruse T., 2005: 27).

Cabe destacar un actor primordial en la movilización: la Coordinadora en Defensa del Agua y de la Vida, una entidad informal que nace con el objetivo de conseguir que tales demandas se cumplieran. Esta se funda el 12 de noviembre de 1999 (Gutiérrez, 2008: 61) en una reunión convocada por la Federación Departamental de Regantes de Cochabamba (la FEDECOR) que ya llevaba unos meses estudiando la ley que permitía la privatización del agua en Cochabamba.

Oscar Olivera (2006: 103), el máximo representante y portavoz de la Coordinadora, describe de la siguiente manera la Guerra del Agua: 
"Los campesinos regantes dieron la voz de alerta, dijeron a las ciudades: nos quieren quitar nuestra agua, nuestra vida. Fueron escuchados por la mayoría, los obreros de las fábricas, los maestros, los transportistas, los comerciantes ambulantes, los desocupados, la gente sencilla y trabajadora, y también algunos ricos como los dueños de hoteles y condominios asistieron a esta convocatoria. Así se organizó la Coordinadora de Defensa del Agua y de la Vida. Luego de cinco meses de lucha, de participación, de organización, de propuestas, de protestas, de indignación, de coraje, etc. se logra desprivatizar la empresa, se expulsa a la transnacional en abril del año 2000 y se impone desde abajo una ley de agua potable asegurando a la gente su derecho al agua como un bien colectivo, como un derecho humano, como dueño de la misma a todos los seres vivos. Ese hecho histórico se denominó la Guerra del Agua.”

La Guerra del Agua figura como uno de los acontecimientos más importantes que abrieron una nueva etapa en la historia de Bolivia, caracterizada por una mayor participación civil en la vida política, económica y social del país (Blanco Fares, 2014: 4); así como con el comienzo del declive del modelo neoliberal impuesto hasta entonces en el país (Cabezas, 2007).

Pero lo que tratamos de averiguar es si el movimiento social sirvió para reavivar la idea de gestionar el agua bajo los principios de bien común, a la vez que se expone cómo ha ido evolucionando esta gestión y cuáles son los retos actuales. La idea de considerar el agua como un bien común parte de una visión no antropocéntrica y busca la confluencia entre las necesidades vitales humanas y el bienestar animal y natural. Además, el hecho de considerarla como un bien común $-\mathrm{y}$ por lo tanto inapropiable o de propiedad común-, supone automáticamente el derecho a una repartición equitativa de éste, así como el derecho al acceso de todos y todas a las tomas de decisiones que le incumben. El estudio incluye, además, una perspectiva de género que permite visibilizar la importancia de las mujeres en la gestión del agua ya que no se quiere obviar que, cuando hablamos de 
agua para consumo humano, son las mujeres las que tienen una relación más directa con ella, las que necesitan constantemente de ese líquido para realizar las tareas que se les han asignado: lavar, cocinar, cuidar, limpiar, etc. (Tapia González, 2018).

El análisis que aquí se plantea es relevante para poder descifrar una forma de gestión completamente equitativa, ya que el agua es el líquido vital el cuál sustenta de forma más explícita la vida en el planeta. Actualmente el agua es uno de los indicadores que implica una mayor desigualdad en muchos países del sur mundial (Tapia González, 2018) y, concretamente, en Cochabamba representa la principal explicación a las desigualdades sociales de la ciudad (Ledo, 2013). Además, cabe tener en cuenta que Bolivia ha vivido, des del final de la Guerra del Agua, un cambio radical de gobierno -el MAS ${ }^{8}$ ganó las elecciones en Bolivia en el año 2006- y un Proceso Constituyente que se inició en 2006 y terminó en 2009: Cuando el MAS entra a gobernar, inicia el proceso para lograr una nueva constitución, reivindicación histórica de muchos movimientos sociales. Así, el Proceso Constituyente busca llevar a la práctica las demandas de los sectores subalternos de la sociedad boliviana y entre ellas también están las que surgieron durante la Guerra del Agua. Aún así, en el marco de la Bolivia actual aún nos encontramos con un país que conserva en gran medida la esencia de auto gestiones tradicionales del recurso -herederas de formas de organización de la vida indígenas- versus un modelo político de Estado más bien centralizador de las decisiones y cuestiones que atañen a la sociedad en general y al recurso agua en concreto. Estado que, aunque el gobierno del MAS busque romper completamente con ciertas dinámicas anteriores, en su esencia proviene de un Estado Liberal Oligárquico impuesto o importado des de Europa durante el

\footnotetext{
8 Movimiento al Socialismo; partido político que lidera Evo Morales. El MAS no fue, en sus inicios, un partido político convencional; sino que provino de la integración de movimientos sociales de carácter indígena campesinos. Salvador Schavelzon (2012: 2) alega que el MAS no era un partido de tipo clásico sino la expresión partidaria del sindicalismo campesino del país.
} 
periodo colonial -del siglo XVI al siglo XIX- (Castro H, 2008). Este hecho abre una multiplicidad de posibilidades a la vez que contradicciones por lo que hace a la gestión del agua, las cuáles dificultan el tener la certeza de cuál es el mejor modelo organizativo. Es por todo ello que resulta de extrema urgencia analizar la situación actual del agua en Bolivia y, concretamente, en Cochabamba.

Para el desarrollo de este estudio se han llevado a cabo un total de 15 entrevistas 9 realizadas a personas directamente relacionadas con la temática del agua y, específicamente, de la Guerra del Agua en Cochabamba.

\section{La gestión del agua como bien común}

Considerar el agua como bien común permite incidir y dar importancia a tres grandes aspectos:

1) considerar el agua como propiedad colectiva, la cual cosa se materializa en una necesaria equidad tanto de acceso como económica;

2) democratizar por completo la gestión, lo cual supone establecer mecanismos horizontales tanto en las tomas de decisiones como en el acceso a la información, a la vez que descentralizar la gestión,

3) y, por último, una gestión con consciencia medioambiental, a través de la cual se dé prioridad a la calidad del agua, tanto antes como después de usada, y se cuiden las fuentes de agua para que el acceso al líquido pueda ser posible tanto para el resto de seres vivos del planeta como para las generaciones futuras. Según Lidia

9 El resultado es el siguiente: se han entrevistado (durante los meses de abril a noviembre de 2019) a 6 mujeres y 9 hombres ${ }^{9}$. Por otro lado, se ha entrevistado a personas afines al MAS -5 de ellas-, a personas más reacias con el gobierno actual -6 de ellas - y a personas que no se posicionan en tal aspecto -4 de ellas-. También se ha tenido en cuenta que estas tuvieran relación con el agua en el momento actual: 3 de ellas trabajan en entidades públicas de dotación de agua -SEMAPA o PMM-, 5 de ellas son investigadoras sobre distintas temáticas relacionadas con el agua, 5 de ellas apoyan o trabajan en entidades autónomas de gestión del agua y 2 de ellas son actualmente activistas; sea porque mantienen vivo el movimiento de la Guerra del Agua o porque buscan expandir y mantener algunos de sus logros. 
Serrano Tur (2013: 52), la idea de agua como bien común engloba la perspectiva de derechos humanos y de protección medioambiental: presupone la condición de inalienabilidad del recurso (no puede ser apropiable) y el control de la comunidad sobre su uso y manejo, siempre teniendo por objetivo la justicia distributiva del bien.

Aunque a lo largo de todos los años de la historia de la humanidad el agua se había gestionado bajo los principios de bien común, "el nacimiento de las tecnologías modernas de extracción del agua ha puesto de relieve el papel del Estado en el manejo del líquido" (Shiva, 2003: 33) además, por su parte "la economía globalizada está cambiando la definición del agua: de ser un bien común a ser uno de privado que puede extraerse y comercializarse libremente" (Shiva, 2003: 32). Por lo tanto, esta forma de ver el agua busca superar la idea de que sea el Estado el dueño del agua y también la idea de agua como bien privado, ya que ambos son enfoques que permiten parcelar el bien y lo hacen fácilmente privatizable (Serrano Tur, 2013: 53). El agua no debe ser poseída sino simplemente usufructuada.

La colectivización es necesaria para evitar que el Estado tenga la facilidad de privatizar el recurso o que la gestión caiga en dinámicas clientelares Pero la mencionada colectivización no debe eximir al Estado de su deber en la provisión de una necesidad objetiva:

"Los derechos comunitarios son necesarios tanto para la ecología como para la democracia. El dominio burocrático de entidades distantes y externas, así como el control del mercado a manos de los negocios y las corporaciones, desmotivan la conservación [...]. Los precios más altos en condiciones de libre mercado no conducirán a la conservación: Dada la tremenda desigualdad económica, es muy probable que los económicamente poderosos desperdicien el agua mientras los pobres pagan el precio. Los derechos de la comunidad son una necesidad democrática imperiosa: hacen que los Estados y los negocios comerciales se responsabilicen y defiendan los derechos del 
pueblo sobre el agua a manera de una democracia descentralizada." (Shiva, 2003: 45).

A continuación pasamos a delimitar las bases sobre las cuales se sustentaría una regulación y gestión del agua como bien común. Para tal elaboración, se tendrá en cuenta tanto la visión andina del Buen Vivir ${ }^{10}$ como la gestión del agua como bien común propiamente dicha, ya que ambas tienen una base muy similar: tienen un carácter altamente comunitario, a la vez que remarcan la importancia del respeto a la naturaleza y de una vida digna para toda la población; destacando la necesidad de proteger a los estratos más pobres de la población.

La gestión del agua como un bien común contempla, para Lluís Basteiro Bertoli, Lidia Serrano Tur et al. (2015: 7), "criterios de solidaridad, cooperación mutua, acceso colectivo, equidad, control democrático y sostenibilidad". Por su parte, Vandana Shiva (2003: 50) habla de la democracia del agua y de algunos principios que esta debe tener. Así, estos principios deben ser la base para la elaboración de una gestión del agua como bien común: (1) El agua es un regalo de la naturaleza $y$, por lo tanto, se debe provocar un impacto mínimo y mantener una democracia ecológica; (2) el agua necesaria para la subsistencia debe ser gratuita, su compraventa viola nuestro derecho a

${ }^{10}$ Forma de organización social con base en las cosmovisiones indígenas. El Buen Vivir "es el resultado de la histórica resistencia de los pueblos originarios ante la asimilación y la destrucción de sus formas de vida por parte de la sociedad occidental" (Rodíguez, 2016: 127). Así, el Buen Vivir es un concepto que se nutre de ámbitos muy diversos, des de la reflexión intelectual a las prácticas ciudadanas y des de las tradiciones indígenas a la academia alternativa (Gudynas \& Acosta, 2011). Por lo tanto, existen diferentes definiciones del concepto; aunque todas tienen ciertos elementos básicos en común, como resume Adriana Rodríguez (2016: 131), las diversas definiciones y explicaciones del Buen Vivir coinciden en ubicar a la vida en el centro, dar prioridad a la comunidad en las relaciones vitales, salir de una visión antropocéntrica; igualando los derechos del ser humano a los de la naturaleza y viendo la vida humana como parte más de la tierra y del ecosistema; y defender la cultura propia des del respeto a las otras culturas, desde la interculturalidad. La conceptualización contemporánea del Buen Vivir, en el fondo es un arma de los pueblos indígenas contra el neoliberalismo (Rodíguez, 2016). 
tal regalo de la naturaleza y niega a los pobres la parte que les corresponde; (3) se debe mantener sostenibilidad ecológica y social: el agua puede acabarse si no se cuida, por lo tanto es importante un uso que no prive a la naturaleza de su reabastecimiento ni tampoco a otras personas de su ración justa; (4) el agua no puede ser poseída, ya que no puede limitarse ni tiene límites. El derecho al agua debe ser solo de usufructo; (5) nadie tiene derecho a utilizar agua en exceso, desperdiciarla o contaminarla.

Por su parte, Huanacuni Mamani (2010: 64) propone una serie de ideas para generar políticas públicas sobre el agua en consonancia con el Buen Vivir: (1) se debe garantizar la disponibilidad del agua con equidad para asegurar la existencia de todos los seres vivos del planeta; (2) se debe definir el agua como un bien público bajo el control de la sociedad. Hay que buscar mecanismos equitativos que respondan de igual forma a las necesidades de la naturaleza y de las comunidades, priorizando la subsistencia, la soberanía alimentaria y el desarrollo local; (3) ninguna empresa o persona particular tiene derecho a apropiarse del agua para fines lucrativos en perjuicio de la colectividad. El agua nunca puede ser tratada como mercancía; (4) Los sistemas de gestión deben tener una visión integral del sistema y el entorno, con tal de garantizar la sustentabilidad del recurso. Además, deben incorporar mecanismos participativos que permitan garantizar la participación social y un acceso equitativo al líquido; (5) las normas legislativas y gestiones del agua deben garantizar la disponibilidad del agua en términos de volumen y calidad, con tal de asegurar la cobertura de las necesidades ecosistémicas y de las comunidades humanas. Así mismo, los gobiernos de los países andinos deben respetar, valorar y apoyar las diversas gestiones comunales del agua y (6) Toda política de inversión pública debe considerar prioritariamente la conservación del recurso, la gestión sustentable y equitativa y el desarrollo local y regional.

Como se puede constatar, se destaca en todo momento la importancia de una gestión bajo control social de la población o comunidad, pero impulsada y apoyada por el Estado. Por lo tanto, en estas páginas 
hablaremos de una gestión del agua que debe encabalgar lo Estatal y lo comunitario en una suerte de nueva democracia real y efectiva por lo que hace a la gestión del agua:

Sólo la titularidad colectiva del agua y el carácter público de los servicios de abastecimiento y saneamiento pueden asegurar el acceso universal a este recurso vital y a estos servicios esenciales, garantizando una gestión integral que resulte socialmente equitativa, ecológicamente sostenible, políticamente democrática y culturalmente aceptable. (Basteiro, Serrano Tur, et al., 2015: 8).

\section{La Guerra del Agua y 19 años después}

A continuación mostramos cuál es la concepción que se desarrolla durante y poco tiempo después de la Guerra del Agua en Bolivia acerca sobre las tres dimensiones antes apuntadas: la propiedad colectiva del agua, la democratización en la gestión y la consciencia medioambiental.

\section{a. Propiedad colectiva del agua}

Por lo que hace a la propiedad del agua, tanto durante como justo después de las movilizaciones, si bien es cierto que a la población movilizada le resulta difícil delimitar en términos prácticos exactamente cómo se debe tratar el agua en este aspecto, lo que sí defienden y tienen claro es que el agua no puede estar en manos privadas:

"Antes el agua se vendía, se usaba como una mercancía. Desde la Guerra del Agua, los ciudadanos decimos: aquí nadie nos vende agua, no nos pueden vender agua. Nos prestan un servicio y nos cobran por el servicio, pero el agua no nos la venden. [...] El agua no se vende, el agua cae del cielo y se almacena en la tierra, es un bien común.” (Entrevista anónima 1, 2019).

En este sentido, algunos de los lemas que más fuerza tuvieron durante la Guerra del agua fueron: El «agua es de todos» o «el agua es vida». Todos ellos aluden a una cierta imposibilidad de apropiación del líquido y, por lo tanto, a una necesidad implícita de distribución equitativa de este: 
Se hizo conciencia no solo de la falta y de la escasez, sino también de que había injusticias en la gestión, distribución y acceso al agua:

“[...] El agua es escasa en Cochabamba y más que escasa, hay una distribución muy mala que se manifestó y se hizo visible en la Guerra del Agua de forma clara y evidente $[\ldots]$. El derecho al agua es un tema que se discutió bastante, no como derecho humano al agua, pero sí el derecho a acceder al agua. En la Guerra del Agua sí que hubo de alguna forma una reivindicación de que el agua era de todos y por lo tanto todos tenían que poder acceder al agua." (Entrevista a Campanini, 2019).

Este segundo aspecto es relevante, ya que indica una gestión con base equitativa y social: todos tenemos derecho a acceder al agua y, por lo tanto, el agua de la que dispone el territorio debe cubrir las necesidades básicas de toda la población para que esta pueda disfrutar de una vida digna.

La situación actual deja mucho que desear, es contraria a las reivindicaciones e ilusiones que surgieron acerca de este punto concreto durante la Guerra del Agua. Si bien la nueva constitución Boliviana dedica un capítulo completo al agua -denominado Recursos Hídricos- donde alega en su texto a la imposibilidad de privatización del agua y a la necesidad de que esta se distribuya de forma equitativa:

"El Estado debe promover el uso y acceso al agua sobre la base de los principios de la solidaridad, complementariedad, reciprocidad, equidad, diversidad y sustentabilidad [...]. El Estado también debe proteger y garantizar su uso prioritario, así como de gestionar, regular y planificar el uso adecuado y sustentable de los recursos hídricos, con participación social y garantizando su acceso a todos sus habitantes." (Vargas Gamboa, 2015: 102).

En la práctica no se ha visto traducido, durante estos años, en una efectiva mejora de las desigualdades en cuanto a la distribución del líquido. Parte de la responsabilidad de este hecho se encuentra en el gobierno municipal el cuál es el responsable, según la legislación, de la dotación de agua en el municipio (Ledo, 2013). Así, la equidad de acceso al líquido sigue siendo inexistente. El área de cobertura de SEMAPA es la zona central y norte del Cercado, por lo tanto, la zona 
sur de la ciudad no dispone de cobertura de agua potable por parte de la empresa municipal, cosa que provoca e implica una desigualdad importante. Las razones a las que suelen alegar SEMAPA y los poderes públicos acerca de la insuficiente cobertura que proporciona la empresa municipal a la ciudad es que no hay suficiente agua para proporcionar el servicio a la zona sur (Vargas Gamboa, 2015). Sin embargo, personas estudiosas del tema lo rebaten:

"Eso son temas políticos. [...] ¿Por qué diablos no tienen los del sur? Es un problema político. [...] Si yo tengo plata, obviamente tengo tanque alto y tanque bajo y ahí todo lo que llega me lo como, ¿sí? pues ya no llega nada al sur. [...] Tendrían que haberse pensado mecanismos de distribución que no hagan que los que más tienen, consuman todo. Eso es un manejo técnico." (Entrevista a Ledo, 2019).

Además, aunque SEMAPA produce agua de buena calidad y potabilizada correctamente, su cobertura del servicio de agua potable es muy baja, solo alcanza al 60\% (AAPS; MMAyA, 2017: 63) de la población del Cercado. Esta poca cobertura es debido a que, por un lado, diversas fuentes aseguran que existe corrupción dentro de la empresa, cosa que provoca la incapacidad de SEMAPA de extender sus redes a la zona sur por falta de excedente económico y, por otro lado, las cañerías actuales necesitan ser renovadas ya que un 35\% (AAPS; MMAyA, 2017: 63) del agua producida por la empresa se pierde por causa de cañerías viejas. Estas son las principales razones por las que SEMAPA no dispone de agua ni de fondos suficientes para aumentar su cobertura. Así, la razón por la que no llega agua a la zona sur hoy, a casi 40 años del surgimiento de los barrios en tal zona, ya no tiene que ver con una incapacidad real de cobertura sino con un abandono claro, por parte de los poderes públicos y la empresa municipal, de tal área por lo que hace al suministro del agua.

Esta situación impulsó el surgimiento de las OLPES. A día de hoy, se estima que en la zona sur de Cochabamba unas dos terceras partes (un $70 \%$ ) de las familias excluidas del servicio público se abastecen a través de ellas (Cabrera J. E., 2018: 206) y que existen más de 600 sistemas 
comunitarios de agua de distintos tamaños. Sin embargo, no existe un control de estos sistemas y, por tanto, no se tienen datos precisos sobre la cobertura real de agua que depende de ellas. Cabe destacar que las OLPES también son sujeto de dinámicas nocivas que resultan en inequidad distributiva, en gran medida debido a la escasez de agua y a una falta de cohesión y visión global del manejo del agua -que debían aportar los poderes públicos y no lo hacen-. Lo que sucede es que, en la práctica, se actúa como si el bien fuera privado, se generan dinámicas de privatización colectiva del bien las cuales impiden una distribución equitativa:

"El tema de hacer pozos y buscar agua conlleva problemas con otras comunidades y sectores. Por eso hemos tenido que buscar agua dentro de nuestro mismo territorio, el territorio delimitado para la OTB. En realidad, el Estado seria el dueño del subsuelo pero nosotros no respetamos, con la delimitación de las OTBs nosotros pensamos que nosotros somos dueños de todo ese territorio pero no es así... Pero entrar en conflicto con OTBs es muy complicado entonces, como te digo, preferimos buscar un espacio que esté dentro de nuestra jurisdicción como OTB.” (Entrevista a Ceballos, 2019).

Así, aquel barrio que dispone de buena agua no la quiere compartir con los otros barrios, cosa que acaba suponiendo que tengan acceso al bien común necesario para la vida sólo aquellas zonas con mayor suerte:

La solidaridad, el elemento fundamental para la cohesión social, “[...] es permanentemente debilitada al existir un contexto en el cual solo los barrios por medio de sus pequeñas redes y propios esfuerzos garantizan el acceso al recurso agua a sus socios, convirtiendo a la acción sobre la gestión y administración del recurso agua en un elemento de cohesión, pero elemento de fractura social y espacial con el resto de la ciudad. La dislocación se genera por la negativa de los vecinos de compartir el recurso agua con otros vecinos y con la población en general." (Cabrera, 2018: 219). 
Tal privatización colectiva del agua está presente en todo el territorio, ya que la falta de visión global y la poca agua de la que disponen supone una constante competición para poder apropiarse de las distintas fuentes de agua:

"Han surgido más conflictos relacionados con el tema del agua, ya que se ha extendido un mal concepto que está muy a parte de la Constitución Política del Estado y es el tema de [...] la propiedad privada de las comunidades sobre los recursos naturales. [...] Últimamente ha habido conflictos en Cochabamba muy serios en este sentido, en que las comunidades que están en la cordillera, donde justamente emergen las aguas des de vertientes a través de los ríos, etc., pues resulta que las comunidades ahora $[\ldots]$ dicen que son propietarios del agua y, por lo tanto, han cortado las fuentes de agua hacia los valles de Cochabamba. [...] Son temas que siguen pendientes hasta el día de hoy y más bien tienden a acrecentarse." (Entrevista a Fernandez, 2019).

Pero la desigualdad más evidente que se deriva de la desordenada forma de distribución explicada viene dada sobre todo por la inequidad en los precios, la cual resulta de una falta de estructuración a nivel global. El hecho es que aquellas personas que no tienen otro remedio que abastecerse a través de los carros aguateros deben dedicar un tanto por ciento de su ingreso familiar muy elevado, cosa que supone un consumo diario completamente insuficiente, como expresa Escarley Torrico (2019) en la entrevista:

“[...]estas personas consumen muy poca agua porque no pueden pagar el agua y eso es todo un problema, de salubridad, salud y todo" así mismo lo expresa el entrevistado Omar Fernández (2019): "Las familias más pobres son las que están pagando el agua más cara y, por lo tanto, hacen un ahorro del agua tal que acaba implicando que no cubran sus necesidades básicas respecto al agua, que tienen que ver con la salud, los saneamientos, la higiene..."

Por lo que hace a los precios del agua en las OLPES, según Carmen Ledo (2013: 102) “Cerca del 50\% de las tarifas son menores a 1 \$ por mes; adicionalmente, un $25 \%$ de las tarifas fijas oscila entre 1 y $2 \$$, lo que revela una estructura tarifaria ostensiblemente más baja que la cobrada por SEMAPA y por los carros aguateros". En cambio, si 
comparamos la forma de abastecerse a través de los carros aguateros y a través de SEMAPA, la realidad es que por solo 2 metros cúbicos del líquido los consumidores de agua de los aguateros pagan 3,8 veces más que lo que pagan los consumidores de SEMAPA por $12 \mathrm{~m}^{3}$ (Ledo, 2013: 99). Además, los carros cisterna suelen abastecer a las familias más pobres. Por tanto, mientras que los consumidores de SEMAPA gastan de media en el consumo de agua entre el 2 y el $3 \%$ de su ingreso familiar, las familias que deben abastecerse a través de los carros cisterna deben pagar entre el 7 y el 10\% (Ledo, 2013: 99). "Los criterios de tarifación que existen en SEMAPA, si bien son creados bajo un principio de solidaridad y justicia social, sin embargo, la falta de atención del servicio a todo el territorio determina que existan mecanismos indirectos y perversos de desigualdad" (Ledo, 2013: 81). A nivel interno, las OLPES también suelen generar situaciones en las que la capacidad adquisitiva de la familia determina el poder de acceder, o no, al líquido. En los casos en los que un nuevo vecino quiere conectarse a un sistema ya hecho, este generalmente debe pagar un monto importante para obtener la conexión, el cual alude al trabajo y capital que todos los otros vecinos ya han dado en sus inicios. En algunos casos, este hecho supone la no posibilidad de conexión para el nuevo vecino, el cuál se queda fuera del sistema, con todo lo que ello supone:

"En las OLPES antiguas [...] la gente que ha estado des del inicio ha puesto mucho trabajo y, entonces, a los nuevos usuarios se les exigen mayores condiciones. Hay, para mí, un juego de derecho [...] se les exige un pago por este trabajo que se hubiera realizado antes y si la familia no tiene, que generalmente son las familias más pobres, entonces no van a tener nunca acceso a la conexión. [...] El Estado, en términos de las cifras, va a decir que este sector ya tiene un comité de agua y ya no tiene que intervenir; pero si tú no puedes cumplir las condiciones que el comité te impone, no vas a ser parte del comité y, por lo tanto, como usuario te quedas en el limbo." (Entrevista a Torrico, 2019).

La construcción del Proyecto Múltiple Misicuni es una de las grandes esperanzas de la población. Durante muchos años, fue objeto de 
promesas por parte de muchos y distintos partidos políticos que no llegaron nunca a desarrollar el proyecto, en parte por sus altos costes. Se trata de una reivindicación histórica de la población cochabambina y alrededores (Ortiz Jimenez, 2005: 6). Su situación actual es la siguiente: la represa está construida des del año 2016 (Empresa Misicuni, 2018), por lo tanto, es el gobierno del MAS el que ha llevado finalmente a cabo este proyecto. Pero actualmente solo consta de una aducción la cual lleva agua de Misicuni hasta SEMAPA. Por lo tanto, de momento queda sin respuesta el saber cómo se organizará la gestión de esa agua y como se construirán las cañerías que faltan, y todavía hoy resulta incierto el que este nuevo proyecto responda a las expectativas y necesidades de la población o no. Por otro lado, las OLPES que sí funcionan de la zona sur de la ciudad no quieren desaparecer y desean mantener una gestión descentralizada, aunque necesitan recibir el agua de Misicuni. Así, la forma en la que se distribuirá toda esta agua ahora almacenada en la cordillera de los andes y su mayor o menor descentralización en la gestión es todavía incierta.

\section{b. Democratización de la gestión}

Otro de los aspectos a destacar es la forma en la que se piensa y se ejecuta la gestión del agua. Con la Guerra del Agua, dos son las ideas que cogen fuerza por lo que hace a la gestión del líquido. Por un lado, se busca que la empresa privatizada vuelva a estar en manos públicas y, por otro lado, se busca reforzar el carácter comunitario que ha tenido la gestión del agua en el país a lo largo de su historia. Así, se dan a conocer las OLPES del sur del Cercado, gestiones completamente descentralizadas de administración del agua. Como aspecto relevante cabe mencionar el reconocimiento que se les da a través de la Ley 2066, la ley modificatoria de la Ley de Agua 2029.

La nueva ley de agua reconoce a las cooperativas y asociaciones de agua como entidades legítimas para la prestación del servicio de agua a sus usuarios. El empoderamiento que se les brindó con la ley, junto con la época de cambio que las impulsaba, propició que el año 2004 
surgiera Asica-Sur (Asociación de Sistemas Comunitarios de Agua del Sur). Asica-Sur es una organización social, de carácter civil y sin fines de lucro. Esta aglutina y representa a diferentes sistemas comunitarios e independientes de agua: Cooperativas, Asociaciones, Comités, OTBs, etc. (Asociación de Sistemas Comunitarios de Agua del Sur, 2004). Sus objetivos, según Asica-Sur (2004: 1) son: “Organizar y fortalecer las experiencias en gestión comunitaria alcanzando su reconocimiento legítimo, jurídico y legal como co-gestores de los servicios básicos, estableciendo un nuevo modelo de gestión" y "desarrollar un proceso de capacitación que logre garantizar, a través de la gestión interna de los Sistemas Comunitarios, la sostenibilidad y continuidad de los servicios de agua, garantizando calidad, cobertura solidaria, costos reales, tarifas justas, difusión y aplicación de la cultura del agua". Esta asociación impulsó enormemente el poder de influencia y negociación de los sistemas comunitarios hacia los poderes públicos y SEMAPA; de forma que, durante los años en que fue más activa, se consiguieron gran cantidad de alcantarillados para distintas comunidades de la zona sur y se lograron convenios con SEMAPA en los casos más necesarios, para que esta vendiera agua en bloque a algunas OLPES.

Por otro lado, por lo que hace al manejo de la empresa pública SEMAPA, justo acabada la Guerra del Agua se abren las puertas a plantear por completo la gestión y organización de esta:

"Después de lograr que parara la privatización, la gente quería una nueva forma de gestión de la empresa, a esta nueva gestión se la llamó público-social y venia de la idea de que sí haya participación del Estado, pero también de la gente" (Entrevista a Olivera, 2019).

En este sentido, a raíz de muchos y diversos debates ciudadanos y con la Coordinadora del Agua encabezando las negociaciones y siendo portavoz de las decisiones, se pone sobre la mesa el mencionado control social de la empresa municipal SEMAPA. Contrariamente a la idea de control social tradicional -la cuál alude a un control hacia la 
población ejercido por los poderes públicos- cuándo se habla de control social en el caso de Cochabamba y su gestión del agua, se hace referencia a un control que proviene des del pueblo y que pretende fiscalizar a los poderes públicos, el cuál defiende una ciudadanía activa y una voluntad, por parte de esta, de llegar a formas democráticas y de repartición del poder de decisión y acción más horizontales. Este control social se materializa en lo que se llamaron los directores ciudadanos, personas votadas por el pueblo en cada distrito las cuales pasaban a formar parte del directorio de SEMAPA con el objetivo de fiscalizar las decisiones que allí se tomaran:

Una de las conquistas fue la implementación de directores ciudadanos como control social en SEMAPA (Entrevista a Hurtado, 2019).

Así, en un espacio donde anteriormente había sido inexistente el acceso por parte de la ciudadanía a la toma de decisiones y a la información, con estos avances observamos una clara democratización y una mejora importante por lo que hace al acceso a la toma de decisiones e información de la población en su conjunto para decidir sobre un asunto que les afecta diariamente, como es la dotación de agua.

En este punto resulta necesario hablar también de si existió, o no, equidad de género. Como se ha especificado en apartados anteriores es sobre todo la mujer la que tiene, en la práctica, una relación más estrecha con el agua debido a que su día a día está muy relacionado con esta y, por tal razón, su conciencia sobre el bien y sobre la generación de una gestión equitativa es mayor. Según Peredo Beltrán (2004: 33) las mujeres durante la Guerra del Agua realizaron tareas vinculadas a sus roles de género (desde cocinar para todos hasta la elaboración de elementos protectores contra gases lacrimógenos), pero también organizaban comités de difusión y visitaban los medios de comunicación con tal de organizar la protesta; sin embargo, en las instancias de dirección donde se tomaban las decisiones y se negociaba con el Gobierno, la presencia de las mujeres fue muy baja. 
"[Durante la Guerra del Agua] había división: las mujeres se quedaban en algunos barrios a cuidar las barricadas y los hombres iban a la plaza. Quién mantiene el cerco es la mujer, pero quien viene a dar la charla y la cara es el hombre [...]. Los portavoces eran varones, [...] las que llevaban comida a la gente que estaba haciendo los bloqueos eran mujeres; [pero] si tú ves las fotos de la Guerra del Agua, vas a ver siempre en frente de la lucha a una mujer... y es que los policías tenían miedo de golpear a una mujer y por eso siempre había una en frente, para desconcertar. Entonces, había estas cositas bonitas también, ¿no? [...]. Y es que las mujeres [...] justamente por su proximidad a las tareas domésticas, ellas saben cuánto cuesta el costo real del agua. Ellas son las primeras que lo sienten." (Entrevista a Olivera, 2019).

Por lo tanto, por un lado se valoró el aporte de las mujeres en los espacios populares y en la lucha, la cual pudo desenvolverse en gran parte gracias a la fuerza y el trabajo de éstas, pero por otro lado, no se consiguieron transformar las relaciones de género en las instancias de poder visibles: entre los portavoces de la Coordinadora en Defensa del Agua y de la Vida sólo hubo una mujer, aquellas personas que realizaban las negociaciones con los poderes públicos fueron siempre hombres y entre los directores ciudadanos que entraron a fiscalizar SEMAPA nunca hubo la presencia de ninguna mujer.

La situación actual resulta más bien desesperanzadora, y los directores ciudadanos actualmente ya no existen. Si bien las OLPES ${ }^{11}$ siguen existiendo y funcionando, para su correcto funcionamiento necesitan un asesoramiento y ayuda concretos por parte de personas expertas que, con la elaboración de la ley 2066 -la nueva ley creada por la Coordinadora justo después de la Guerra del Agua- y el establecimiento de cierta institucionalidad -impulsada también por la Coordinadora-, durante los años posteriores a las movilizaciones parece que se estaba logrando: se establecieron licencias y fiscalizaron

11 Tales sistemas realizan su manejo de forma horizontal, su máximo órgano de toma de decisiones son las asambleas que se realizan con todos los socios generalmente una vez al mes, cosa que supone que los beneficiarios sean participantes activos de su realidad. Las OLPES son un muy buen ejemplo de una gestión descentralizada y llevada a cabo por la comunidad; pero sin apoyo institucional. 
y registraron muchas de las OLPES de la zona sur. Sin embargo, el avance del fortalecimiento de estas gestiones comunitarias fracasó. Actualmente, estas no reciben ningún apoyo y tampoco existe un control desde los poderes públicos:

"Por parte del Estado [...] por lo menos aquí en la ciudad, en los barrios urbanos y periurbanos, $[\ldots]$ no se está fortaleciendo a los comités... al menos como comité de agua no hemos notado ninguna mejora, el Estado no nos ha dado nada... [...] Actualmente [...] legalmente estamos reconocidos con una licencia. Eso te da la seguridad jurídica digamos, pero no te da lo otro [...]. El Estado debería tomar esto en serio; [...] estamos en la Constitución política del Estado, por tanto deberían hacer una planta de potabilización, pero no se hace. Hasta las redes tienen ya muchos años y en esto debería invertir el Estado, porque no se les puede pedir tanto a los vecinos. Pero ni modo... que vamos a hacer, tenemos que poner todo nosotros y seguimos funcionando..." (Entrevista a Ceballos, 2019).

Así, en la práctica se las ha abandonado a su suerte. Como expresa en la entrevista Oscar Ajhuacho (2019):

“[...] Aunque al Estado le conviene que haya estas asociaciones para poder disminuir la inversión pública. De otra forma no llegarían a cubrir toda la demanda de agua. Por lo tanto, tales gestiones comunitarias no han recibido el apoyo que demandaban y necesitaban para construir y manejar sus sistemas de forma que respondan a una descentralización de la distribución del líquido realmente democrática y empoderadora; sino que siguen siendo respuestas desesperadas por parte de la población ante la inacción de los poderes públicos de responder a sus necesidades."

Por otro lado, las OLPES han perdido capacidad de negociación e interpelación al Estado en los últimos años. Actualmente Asica-Sur está prácticamente desarticulada. Las razones a las que se alegan son varias; por un lado, la pérdida de comités de agua a lo largo del tiempo ha debilitado a la institución matriz; por otro lado, se cree que hubo cierta corrupción por parte del máximo dirigente el cual se mantuvo muchos años en el poder; según el entrevistado Gastón Ceballos (2019): 
"es muy peligroso que un dirigente, aunque sea de base [...], se mantenga muchos años: generas un paternalismo [...]; siempre hay que tratar de que se cambie porque cuando uno se eterniza en el poder empieza a haber corrupción"

Y porque, por último, cuando llegó el MAS al poder el movimiento fue, en parte, cooptado por el Estado; según la entrevistada Marcela Olivera (2019), "[Asica-Sur] ha empezado a desaparecer cuando el MAS ha llegado al gobierno, porque ha cooptado la organización y la ha neutralizado".

Por lo que hace al control social que se quiso promover en SEMAPA, como ya se ha avanzado en párrafos anteriores, a día de hoy está completamente desarticulado. La gestión de los directores ciudadanos duró, aproximadamente, dos mandatos, hasta el 2008 (Entrevista a Hurtado, 2019). La razón que se alega es la corrupción por parte de los directores ciudadanos, sin embargo, también los directores ciudadanos alegan corrupción por parte de la alcaldía. La realidad es que, aunque seguramente hubo corrupción por parte de ambos, eso no impidió que la alcaldía continuara fiscalizando la empresa pero sí implicó el fin del control social por parte del pueblo hacia ésta. Por lo tanto, en comparación a los avances que se habían conseguido con la Guerra del Agua, con el paso del tiempo se ha perdido democratización en la gestión y se ha centralizado el poder en el aparato público.

\section{c. Consciencia medioambiental}

Durante y después de la Guerra del agua se puede hablar del surgimiento de una consciencia acerca del agua y su ciclo de vida, la cual se hizo más fuerte en los debates posteriores a la Guerra del Agua: "el agua cae del cielo y se almacena en la tierra; es un bien común" (Entrevista anónima 1, 2019). Aunque Cochabamba siempre haya tenido una consciencia especial, la Guerra del Agua significa un aumento de tal consciencia en espacios -sobre todo la zona centro y norte- donde hasta el momento no había sido tan fuerte. Sin embargo, las propuestas prácticas que salieron de todas estas reflexiones fueron prácticamente inexistentes. 
Es cierto que se buscaba una gestión del agua que viniera de las comunidades y "que el agua tenga un carácter social comunitario [...] tiene que ver, también, con la parte ecológica" (Entrevista a Fernandez, 2019), pero no se planteó cómo hacerlo teniendo en cuenta la renovación de las fuentes de agua o la repurificación del agua usada, etc. (como expresa Omar Fernández (2019) en la entrevista). La dimensión ecológica tiene un largo recorrido y genera enormes desigualdades las cuales a día de hoy no han disminuido, sino que se acrecientan cada vez más. Aún en 2019, la mayoría de los habitantes de la zona sur viven en condiciones de gran vulnerabilidad por la falta de servicios básicos. Tal vulnerabilidad queda acrecentada debido la alta concentración de factores contaminantes que se encuentran en el área; la mayoría de fuentes de contaminación de la ciudad están en el sur: la planta municipal de tratamiento de aguas servidas, el botadero municipal, etc. (Linsalata L., 2014a). Todas estas fuentes de contaminación representan un riesgo enorme para la salud de la población, en gran medida debido a que contaminan las aguas subterráneas de la zona, prácticamente única fuente de agua de los pobladores del lugar. El resultado es una diferencia de 20 años en esperanza de vida entre los barrios del norte y el sur de la ciudad: mientras que en los distritos 10, 11 y 12 la esperanza de vida actual es de unos 70 años, en los distritos 7, 8, 9 y 14 la esperanza de vida es de unos 50 (Ledo, 2019). Este hecho supone una desigualdad ambiental estructural que marca la vida $-\mathrm{y}$ muerte- de las personas dependiendo de su lugar de residencia.

A nivel concreto, y por parte de los diversos actores encargados de ofrecer el servicio de agua para consumo humano a la ciudad, se dan otros problemas de carácter ambiental. Por un lado, SEMAPA utiliza de forma correcta sus fuentes de suministro pero no hace una buena gestión del agua usada: solo el 56\% de las aguas residuales se tratan correctamente (AAPS; MMAyA, 2017: 63). La razón de ello, es existe tan solo una planta de tratamiento (Albarrancho) y ésta no tiene suficiente capacidad, además de no contar con un buen 
mantenimiento. Por lo tanto, gran parte del agua que llega a la planta de tratamiento se deja ir al rio Rocha ${ }^{12}$ contaminada. Por otro lado, las OLPES no disponen de un control y fiscalización global: no tienen una visión y organización determinada para todas ellas en su conjunto -que deberían aportar los poderes públicos-, por lo que se produce una desaparición de las aguas subterráneas y de contaminación de estas:

"En el fondo el drama es que casi dos terceras partes de la población se abastece de agua subterránea en el área metropolitana. [...] La expansión de la mancha urbana lo que ha hecho es impermeabilizar el acuífero. [...] Prácticamente de las 40.000 hectáreas del acuífero, casi 20.000 ya están impermeabilizadas. [...] Entonces, muchos de los pozos se secan o las profundidades son extremadamente altas para conseguir agua. La situación es compleja, es complicada. Muchos de los pobres que a duras penas logran conseguir 20.000 dólares para arreglar su pozo, dado el desorden y la falta técnica en la explotación y control del agua subterránea, se les secan los pozos. Entonces, mucha de esta inversión va a saco roto, a nada." (Entrevista a Ledo, 2019)

Por otro lado, el alcantarillado no cubre toda el área, por lo que muchas casas tienen pozos sépticos mal sellados o, simplemente, tiran el agua usada directamente a la calle; cosa que contamina directamente los acuíferos que ellos mismos utilizan para conseguir el agua. Por lo tanto, nos encontramos con un agua subterránea muy contaminada $y$, en la mayoría de los casos, no apta para el consumo. Pero las OLPES, separadas y por sí solas, no tienen la capacidad de construir plantas de potabilización ni alcantarillados o plantas de tratamiento para las aguas servidas. Es sobretodo aquí donde el Estado debe tener un papel relevante y central en el apoyo e impulso de una descentralización efectiva y equitativa de la gestión del bien (García Linera, 2010). Por lo que hace a la consciencia acerca del bien y de su uso, en la zona sur se hace un gran rehuso del agua, ya que la posibilidad de adquisición del bien que tienen es muy baja. Según la entrevistada Escarley Torrico (2019), "los comités y los que toman agua del

${ }^{12}$ Río que pasa por el centro de la ciudad de Cochabamba. 
aguatero consumen muchísimo menos de, digamos, de lo que está determinado en términos de las organizaciones internacionales para una situación de guerra". Los bajos niveles de agua de los que disponen dificultan enormemente la vida de estas personas, sobre todo de las mujeres, ya que "si el agua escasea o está contaminada, son ellas [las mujeres] las que tienen que invertir más tiempo en conseguirla, lo que agudiza las desigualdades de género" (Tapia González, 2018: 241). Además, el ahorro de esta agua -el cuál no se hace de forma voluntaria sino por necesidad-implica que su tiempo destinado propiamente a las tareas domésticas -lavar, cocinar, etc.- aumente considerablemente (Entrevista a Torrico, 2019).

Por lo tanto, nos encontramos con una realidad que no corresponde a un modelo de gestión pensado para que también puedan tener acceso al agua tanto las generaciones futuras como el resto de vida que forma parte de la zona -plantas, animales y ecosistemas-. Por un lado, la estructuración de la ciudad de Cochabamba implica, intrínsecamente, una desigualdad ecológica importante. Por otro lado, la falta de visión holística de la gestión del agua implica que tales desigualdades se acentúen y que no se tomen en cuenta aspectos básicos para un cuidado del ciclo del agua. Por lo tanto, una descentralización de la gestión del líquido mal hecha implica que cada zona puede adoptar decisiones (de consumo o de gestión del recurso) sin tener en cuenta las consecuencias de tal acción en el resto de la ciudad o zonas. Así, los acuíferos cada vez tienen menos agua, el agua restante cada vez está más contaminada y no existe una reutilización efectiva del agua usada.

\section{Conclusiones}

Las ideas sobre la gestión del agua que surgieron durante la Guerra del Agua empezaron a ser efectivas en un primer momento, justo después de las movilizaciones, pero poco a poco se fueron perdiendo -ya no hay directores ciudadanos en SEMAPA, no se están expandiendo las redes de agua hacia el sur y no hay apoyo ni cogestión entre los poderes públicos y las OLPES-, de tal forma que actualmente la 
situación de la gestión del agua se encuentra casi en la misma situación que estaba antes de la Guerra. Por lo tanto, en su forma práctica, la gestión actual del agua en Bolivia queda lejos de la idea de bien común aquí expuesta. Esto en gran medida se explica por una pérdida de influencia del movimiento el agua hacia los poderes públicos que toman toman las decisiones. Por un lado, la movilización de la población fue perdiendo fuerza a medida que avanzaba el tiempo; resulta difícil mantener un nivel de deliberación y acción ciudadana intensa durante un período largo de tiempo:

Cochabamba no ha logrado resolver el uso de recursos públicos con formas de gestión social y comunitaria para satisfacer una necesidad común. Cochabamba se lo impuso como meta, pero llegó a un límite de que la gente deliberara permanentemente: delibera colectivamente en momentos específicos, durante la gran movilización, la gran marcha y el gran Cabildo pero luego regresa a sus casas porque tiene cosas que hacer (García Linera, 2010: 25).

Por otro lado, el gobierno del MAS ha tendido a cooptar los distintos movimientos sociales y sus líderes, entre ellos el movimiento nacional que se creó alrededor del agua. El MAS, el "gobierno de los movimientos sociales", atrajo al movimiento nacional del agua (Crespo, 2010: 52). Así, muchos de sus líderes pasaron a formar parte del aparato estatal, con la consecuente eliminación de la posibilidad de tener una visión crítica hacia las decisiones que se tomaban des del poder político. Este hecho supuso una desmovilización y pérdida de poder del movimiento, dificultando su capacidad autónoma y legitimando políticas gubernamentales que no favorecían las demandas iniciales del movimiento. De esta forma, se desarticuló la presión de la sociedad civil hacia el poder político y la capacidad de influencia de la población hacia aquellos que toman las decisiones respecto a la gestión del agua.

Por último, cabe destacar que todavía existen límites organizativos para poder darle consistencia y sistematicidad al ámbito participativo y a la confluencia y cooperación entre Estado y comunidad; base de una 
gestión del agua como bien común. En este sentido, será necesario seguir investigando en esta línea, con el objetivo de encontrar soluciones efectivas que permitan una participación real de la población en aquello que les afecta directamente y nos lleven a una verdadera democracia promovida por el Estado, la cual impulse una gestión del agua bajo las bases de bien común aquí expuestas.

\section{Bibliografía}

AAPS; MMAyA. (2017). Indicadores de desempeño de las EPSA reguladas en Bolivia. La Paz: Estado Plurinacional de Bolivia.

Asociación de Sistemas Comunitarios de Agua del Sur. (2004). GLOOBAL. Recuperado el marzo de 2019,

http://www.gloobal.net/iepala/global/fichas/ficha.php?id=29868\&entidad =Agentes\&html=1

Basteiro, Lluís., Serrano Tur, Lídia. et al. (2015). Negocios insaciables: Estado, transnacionales, derechos bumanos y agua. España: Agencia Andaluza de Cooperación Internacional para el Desarrollo (AACID).

Cabezas, Marta. (2007). Caracterización del "ciclo rebelde" 2000-2005. En J. Espasadín, \& P. Iglesias, Bolivia en movimiento: Acción colectiva y poder político (págs. 189-219). España: Viejo Topo.

Cabrera, Juan. E. (2018). Fragmentación urbana por medio de redes de agua: el caso de Cochabamba, Bolivia. Territorios, 203-224.

Castro H, Guillermo. (2008). Nota para una historia del pensar de los latinoamericanos. En A. E. Ceceña, De los saberes, de la emancipación y de la dominación (págs. 54-69). Buenos Aires: CLACSO.

Coordinadora en Defensa del Agua y de la Vida. (2000). Antecedentes de la Guerra del Agua. Cochabamba.

Crespo, Carlos. (2010). El Movimiento Nacional del Agua boliviano: de la resistencia a la cooptación (2000-2007). En C. González, \& F. Poupeau, Modelos de gestión del agua en los Andes (págs. 45-58). Bolivia: Actes \& memoires.

Crespo, Carlos. (2000). La Guerra del Agua en Cochabamba: movimientos sociales y crisis de dispositivos del poder. Debates ambientales - Agua, $52-70$. 
Empresa Misicuni. (2018). Misicuni: el Sueño hecho realidad. Cochabamba: Ministerio de Medioambiente y Agua.

Galeano, Eduardo. (2013). Las venas abiertas de América Latina. Madrid: Siglo XXI.

García Linera, Álvaro. (2010). Estado y comunidad. En F. Pouepau, \& C. González, Modelos de gestión del agua en los Andes (págs. 23-26). Bolivia: actes \& memoires.

Gudynas, Eduardo \& Acosta, Alberto. (2011). El buen vivir más allá del desarrollo. Revista Quehacer, 70-83.

Gutiérrez, Raquel. (2008). Los ritmos de Pachakuti: movilización y levantamiento popular-indígena en Bolivia (2000-2005). Buenos Aires: Tinta Limón.

Huanacuni Mamani, Fernando. (2010). Buen Vivir / Vivir Bien: Filosofias, politicas, estrategias y experiencias regionales andinas. La Paz: Coordinadora Andina de Organizaciones Indígenas.

INE. (2012). Instituto Nacional de Estadística de Bolivia. Obtenido de http://datos.ine.gob.bo/binbol/RpWebEngine.exe/Portal?BASE= CPV2012COM/\&lang $=\mathrm{ESP}$

Kruse, Thomas. (2005). La Guerra del Agua en Cochabamba, Bolivia: terrenos complejos, convergencias nuevas. En E. De La Garza Toledo, Sindicatos y nuevos movimientos sociales en América Latina (págs. 85-119). México, D.F.: Clacso.

Kruse, Thomas \& Vargas, Humberto. (2000). Las victorias de abril: una bistoria que aún no concluye. Cochabamba.

Ledo, Carmen. (2019). Agua para comsumo humano - indicador de la desigualdad y vulnerabilidad en la ciudad de Cochabamba. Seminario sobre politicas y estudios sobre agua en Bolivia. Cochabamba: UMSS / CEPLAG.

Ledo, Carmen. (2013). El agua nuestra de cada dia: Retos e iniciativas de una Cochabamba incluyente y solidaria. Cochabamba: UMSS; CEPLAG.

Linsalata, Lucía. (2014a). Agua en Común: La gestión comunitaria del agua en la zona sur de Cochabamba. Ladradorxs de agua.

Linsalata, Lucía. (2014b). Ni público ni privado: común. Prácticas y sentidos de la gestión comunitaria del agua en la zona sur de Cochabamba en Bolivia. En C. Composto, \& M. Lorena Navarro, Territorios en disputa: despojo capitalista, luchas en defensa de los bienes comunes naturales $y$ 
alternativas emancipatorias para América Latina (págs. 249-266). México, D. F.: Bajo Tierra Ediciones.

Olivera, Oscar. (2006). La guerra por el agua en Cochabamba y la construcción de espacios de rebelión y recuperación de nuestras voces. En Robert Grosse, Carlos Santos, Javier Taks, \& Stefan Thimmel, Las canillas abiretas de América Latina II: La lucha contra la privatización del agua y los desafios de una gestión participativa y sustentable de los recursos hidricos (p. 103-106). Montevideo: Casa Bertolt Brecht.

Ortiz Jimenez, Rafael Marcos. (2005). La gestión del agua en Cochabamba Bolivia. Una historia agitada. Promoviendo la inclusión social en las áreas urbanas: políticas y prácticas. Cochabamba: Universidad Mayor de San Simón.

Peredo Beltrán, Elisabeth. (2004). Mujeres del Valle de Cochabamba: Agua, privatización y conflicto. Global Issue Papers.

Rodíguez, Adriana. (2016). Teoría y práctica del Buen Vivir: Orígenes, debates conceptuales y conflictos sociales. El caso de Ecuador. Bilbao: Universidad del País Vasco.

Schavelzon, Salvador. (2012). El nacimiento del Estado Plurinacional de Bolivia. Etnografía de una Asamblea Constituyente. La Paz: Plural editores.

SEMAPA. (2017). SEMAPA clara y transparente. Consultado en julio / 2019, en http://www.semapa.gob.bo/historia/47

Serrano Tur, Lidia. (2013). Aguas dulces y derecho internacional: el agua como bien común y como derecho bumano des de la perspectiva del desarrollo sostenible. Barcelona: Universitat Pompeu Fabra.

Shiva, Vandana. (2003). Las guerras del agua: privatización, contaminación y lucro. Mexico: Siglo XXI editores.

Tapia González, Aimé. (2018). Mujeres indígenas en defensa de la tierra. Madrid: Ediciones Cátedra.

Thompson Hines, Sarah. (2015). Dividing the waters: Hot power, property and protest transformed the waterscape of Cochabamba, Bolivia, 1897-2000. Berkeley: University of California.

Vargas Gamboa, Nataly. (2015). ¿Qué ha pasado con el agua en el nuevo Estado Plurinacional de Bolivia? América Latina Hoy, 95-111.

Villegas, Pablo. (2010). La desnacionalización del estado boliviano y sus recursos naturales. En E. González, \& M. Gandarillas, Las multinacionales en Bolivia (págs. 17-41). Barcelona: Icaria editorial. 
Anexo: Perfil de las personas entrevistadas

\begin{tabular}{|c|c|}
\hline $\begin{array}{l}\text { Persona } \\
\text { entrevistada }^{13}\end{array}$ & Perfil de la persona entrevistada \\
\hline $\begin{array}{l}1^{\mathrm{a}} \\
\text { Entrevistada } \\
\text { (Anónima 1) }\end{array}$ & $\begin{array}{l}\text { Abogada. Fue asesora legal del directorio del Servicio Municipal de Agua } \\
\text { Potable y Alcantarillado Sanitario de Cochabamba (SEMAPA) durante } 5 \\
\text { años, del } 2009 \text { al } 2013 \text {. Actualmente, lleva } 6 \text { años siendo coordinadora del } \\
\text { directorio de la empresa Misicuni, empresa estatal que se creó con el } \\
\text { objetivo de efectuar y, posteriormente, gestionar el proyecto hídrico e } \\
\text { hidroeléctrico de la presa de Misicuni. }\end{array}$ \\
\hline $\begin{array}{l}2^{\mathrm{a}} \\
\text { Entrevistada } \\
\text { Marcela } \\
\text { Olivera }\end{array}$ & $\begin{array}{l}\text { Miembro de la Coordinadora del Agua y de la Vida durante la Guerra del } \\
\text { Agua en Cochabamba. Actualmente trabaja para una organización con } \\
\text { sede en Estados Unidos, llamada Food and Water Watch, que defiende } \\
\text { temas relacionados con el agua y la soberanía alimentaria. Concretamente } \\
\text { coordina la Red Vida, una red intra americana de organizaciones que } \\
\text { trabajan por la defensa del agua, contra la privatización y a favor de } \\
\text { alternativas a las gestiones del agua tradicionales. }\end{array}$ \\
\hline $\begin{array}{l}3^{\circ} \\
\text { Entrevistado } \\
\text { Marcelo } \\
\text { Rojas } \\
\text { "E1 } \\
\text { Banderas" }\end{array}$ & $\begin{array}{l}\text { Fue un destacado "Guerrero del Agua" }{ }^{14} \text { durante las movilizaciones } \\
\text { contra la privatización del bien. Cuando acabó la Guerra del Agua entró a } \\
\text { trabajar en SEMAPA y sigue trabajando en la empresa municipal des de } \\
\text { entonces. Actualmente es jefe responsable de mantenimiento de } \\
\text { estructuras y edificaciones de la empresa. También participó de los } \\
\text { distintos movimientos sociales que hubo alrededor del país después de la } \\
\text { Guerra del Agua (la Guerra del Gas, el Impuestazo, etc.) y realiza apoyos } \\
\text { voluntarios a los barrios con más necesidades relacionadas con el bien. } \\
\text { Coordina, junto con otros "Guerreros", trabajo orgánico entre } \\
\text { comunidades y los "Guerreros del Agua". }\end{array}$ \\
\hline $\begin{array}{l}4^{\mathrm{a}} \\
\text { Entrevistada } \\
\text { Escarley } \\
\text { Torrico }\end{array}$ & $\begin{array}{l}\text { Socióloga que ha trabajado en los últimos años en el Centro de } \\
\text { Documentación e Información de Bolivia }\left(\mathrm{CEDIB}^{15}\right) \text { como investigadora } \\
\text { en el área urbana y se ha especializado en políticas urbanas, sobre todo las } \\
\text { efectuadas durante el período de la época neoliberal: del } 1985 \text { hasta el } \\
\text { 2000. También trabaja de manera directa con varios comités de agua; }\end{array}$ \\
\hline
\end{tabular}

13 Que se dé a conocer el nombre de la persona entrevistada o no se haga, depende de la voluntad específica de cada persona entrevistada.

14 "Guerreros del Agua" se llamó a los jóvenes que en gran número asaltaron las calles y la plaza principal de Cochabamba efectuando los bloqueos y las manifestaciones multitudinarias de abril de 2000 durante la llamada Guerra del Agua. (Blanco Fares, 2014, p. 12)

${ }^{15}$ CEDIB es una organización civil sin ánimo de lucro que brinda, desde 1970, servicios de información y consulta documental sobre temas sociales de Bolivia y América Latina con una mirada crítica. (CEDIB, 2017).

\section{U \\ B ANUARI DEL CONFLICTE SOCIAL 2018}

DOI. 10.1344/ACS2019.8.10 


\begin{tabular}{|c|c|}
\hline & $\begin{array}{l}\text { realizando acompañamiento, proyectos educativos, ayudando en la } \\
\text { organización de éstos... Realizó una investigación sobre las consecuencias } \\
\text { de la privatización de los servicios de agua en Bolivia. }\end{array}$ \\
\hline $\begin{array}{l}5^{\circ} \\
\text { Entrevistado } \\
\text { Ramiro } \\
\text { Saravia }\end{array}$ & $\begin{array}{l}\text { Participó activamente en la Guerra del Agua a través de su organización: } \\
\text { La Red Tinku. Es director y coordinador de ésta. La Red Tinku nace el } \\
\text { año 1998. Se trata de una organización político cultural: busca hacer } \\
\text { educación política a través de la cultura. Actualmente, des del fin de la } \\
\text { Guerra del Agua, son los organizadores y gestores de las asambleas que se } \\
\text { practican cada lunes en la plaza principal de la ciudad de Cochabamba con } \\
\text { el objetivo de realizar educación política. Son los que continúan la } \\
\text { movilización política en la plaza, la cual se originó con la Guerra del Agua. }\end{array}$ \\
\hline $\begin{array}{l}6^{\circ} \\
\text { Entrevistado } \\
\text { Carlos } \\
\text { Crespo }\end{array}$ & $\begin{array}{l}\text { Sociólogo, investigador y docente de la Universidad Mayor de San Simón } \\
\left(\text { UMSS }^{10}\right) \text {. Estudia el tema del agua des de su tesis de maestría; bajo el } \\
\text { marco teórico de la ecología política. Estudia los conflictos por el agua en } \\
\text { términos de relaciones de poder y, muchas veces, des de una perspectiva } \\
\text { ambientalista; bajo un paradigma más bien anarquista. Ha estado } \\
\text { siguiendo permanentemente los conflictos por en agua en el valle de } \\
\text { Cochabamba des de su tesis de maestría, en la década de los } 90 \text {. La tesis } \\
\text { doctoral la hizo sobre la Guerra del Agua. También apoyó a la } \\
\text { Coordinadora del Agua y de la Vida durante las movilizaciones y participó } \\
\text { en la discusión sobre la creación del Ministerio del Agua, ya con el } \\
\text { gobierno del MAS. }\end{array}$ \\
\hline $\begin{array}{l}7^{\circ} \\
\text { Entrevistado } \\
\text { Omar } \\
\text { Fernández }\end{array}$ & $\begin{array}{l}\text { Fue dirigente, durante } 20 \text { años, de distintas organizaciones de riego y agua } \\
\text { potable en la zona circundante a Cochabamba. En } 1997 \text { funda la } \\
\text { Federación Departamental de Regantes de Cochabamba (FEDECOR). } \\
\text { Durante los conflictos de la Guerra del Agua, fue la FEDECOR quien } \\
\text { impulsó la Coordinadora del Agua y de la Vida y él fue uno de los } \\
\text { portavoces de la Coordinadora. Acabados los conflictos, es parte activa en } \\
\text { la formación de una coordinadora del agua a nivel nacional, la } \\
\text { Coordinadora Nacional del Agua y, a través de esta, formó parte de la } \\
\text { Asamblea Constituyente, ya con el MAS en el poder. También ayudó a } \\
\text { constituir el Ministerio del Agua y toda la institucionalidad alrededor de } \\
\text { éste relacionada con el agua. Así mismo, estuvo de senador por } \\
\text { Cochabamba dentro del gobierno del MAS. Actualmente, después de } \\
\text { dejar de formar parte del gobierno de forma voluntaria, trabaja realizando } \\
\text { asesoramientos y proyectos sobre agua, cultivos y medio ambiente para las } \\
\text { comunidades y pueblos de la zona. }\end{array}$ \\
\hline $\begin{array}{l}8^{\mathbf{a}} \\
\text { Entrevistada } \\
\text { Carmen Ledo }\end{array}$ & $\begin{array}{l}\text { Economista, con una maestría en demografía y doctorada. Actualmente es } \\
\text { profesora de la Universidad Mayor de San Simón. Es experta en } \\
\text { desigualdades, segregación en las ciudades y pobreza. Entra en la temática } \\
\text { del agua como demógrafa siendo parte investigadora en el plan }\end{array}$ \\
\hline
\end{tabular}

${ }^{16}$ Universidad pública de Cochabamba. 


\begin{tabular}{|c|c|}
\hline & $\begin{array}{l}\text { metropolitano de agua para la ciudad de Cochabamba del año } 88 \text {. A partir } \\
\text { de entonces el agua se vuelve su mayor interés académico. Realiza su } \\
\text { doctorado sobre las desigualdades en la ciudad y, como variable que más } \\
\text { desigualdad provoca en Cochabamba, le surge el agua. Después de su } \\
\text { doctorado, vuelve a replicar el estudio que había hecho en el } 88 \text { acerca de } \\
\text { la situación del agua. Participa en distintos foros mundiales del agua y } \\
\text { actualmente sigue investigando temáticas de agua y desigualdades en el } \\
\text { departamento de Cochabamba. }\end{array}$ \\
\hline $\begin{array}{l}9^{\circ} \\
\text { Entrevistado } \\
\text { Ángel } \\
\text { Hurtado }\end{array}$ & $\begin{array}{l}\text { Presidente de la Cooperativa de Agua Potable } 1^{\circ} \text { de Mayo, una Operadora } \\
\text { Local a Pequeña Escala (OLPE) de la zona sur del Cercado. Durante la } \\
\text { Guerra del Agua, fue uno de los dirigentes y cabezas organizativas de la } \\
\text { movilización en el barrio } 1^{\circ} \text { de Mayo (parte importante de la zona sur). } \\
\text { Posteriormente, con la creación de Asica-Sur entró a formar parte del } \\
\text { directorio de la asociación. También fue uno de los directores ciudadanos } \\
\text { elegidos para fiscalizar el directorio de SEMAPA durante la última gestión } \\
\text { ciudadana: la del } 2007 \text { / } 2008 \text {. }\end{array}$ \\
\hline $\begin{array}{l}10^{\mathrm{a}} \\
\text { Entrevistada } \\
\text { (Anónima 2) }\end{array}$ & $\begin{array}{l}\text { Trabajó con la federación de regantes FEDECOR. Posteriormente, } \\
\text { también entró a formar parte de la Coordinadora del Agua y de la Vida } \\
\text { durante las movilizaciones. Ella fue la única mujer que formó parte de los } \\
\text { portavoces de la Coordinadora del Agua y de la Vida durante la Guerra } \\
\text { del Agua. Acabada la Guerra del Agua, siguió trabajando en temas } \\
\text { relacionados con el agua: proyectos de riego, la conformación de } \\
\text { normativas estatales, etc. Así mismo, participó activamente en la } \\
\text { conformación de la nueva constitución boliviana del } 2009 \text { a través de la } \\
\text { Asociación Nacional de Regantes y Sistemas Comunitarios de Agua } \\
\text { Potable y Saneamiento de Bolivia, la ANARESCAPYS; de la cual también } \\
\text { forma parte. }\end{array}$ \\
\hline $\begin{array}{l}11^{\circ} \\
\text { Entrevistado } \\
\text { Oscar } \\
\text { Campanini }\end{array}$ & $\begin{array}{l}\text { Sociólogo y director actual del Centro de Documentación e Información } \\
\text { de Bolivia (CEDIB). Su experiencia como investigador ha estado siempre } \\
\text { vinculada a la temática del agua: } \mathrm{Al} \text { análisis sobre la problemática del agua } \\
\text { en Cochabamba y Bolivia en general. Se ha centrado principalmente en } \\
\text { políticas públicas y normativa alrededor del agua. Participó, como } \\
\text { estudiante, en la Guerra del Agua. }\end{array}$ \\
\hline $\begin{array}{l}12^{\circ} \\
\text { Entrevistado } \\
\text { Gastón }\end{array}$ & $\begin{array}{l}\text { Exdirigente de la Asociación de Agua Potable y Alcantarillado Barrio San } \\
\text { Miguel, una OLPE de la zona sur del Cercado. Trabajó en la Fundación } \\
\text { Abril }{ }^{17} \text { y posteriormente también formó parte del Comité Técnico de }\end{array}$ \\
\hline
\end{tabular}

${ }^{17}$ La fundación Abril nace el año 2002, después de la Guerra del Agua. Como producto de esta lucha, la Coordinadora del Agua recibe, el 24 de abril de 2001, un premio de125.000 \$, promovido por la ONG Goldman. Mismo que es destinado en su totalidad a la creación de una institución que sea el brazo institucional de las organizaciones sociales. Su misión es impulsar y desarrollar colectivamente procesos participativos, democráticos y alternativos en las reivindicaciones laborales 


\begin{tabular}{|l|l|}
\hline Ceballos & $\begin{array}{l}\text { Recursos y Licencias de Cochabamba (CTRL), comité de carácter público } \\
\text { que regulaba a las OLPES. Actualmente es un usuario y beneficiario más } \\
\text { del sistema de agua potable de San Miguel. Participó de la Guerra del } \\
\text { Agua junto con todo el barrio, el cuál fue muy activo durante el conflicto. }\end{array}$ \\
\hline $\begin{array}{l}\mathbf{1 3}^{\mathbf{o}} \\
\text { Entrevistado } \\
\text { Oscar }\end{array}$ & $\begin{array}{l}\text { Economista y sociólogo, investigador académico de las distintas formas de } \\
\text { economía social y solidaria existentes en Bolivia. Habitante de Villa } \\
\text { Sebastián Pagador, un barrio de la zona sur este del Cercado. Actualmente } \\
\text { es vicepresidente de la Asociación de Producción y Administración de }\end{array}$ \\
Agua y Saneamiento (APAAS), la asociación que administra el agua \\
potable y saneamiento del barrio Villa Sebastián Pagador. Se trata de una \\
de las OLPES más antiguas del Cercado.
\end{tabular}

y en la gestión del agua como bien común a través de acciones de cambio basados en la organización, gestión, educación, investigación y la denuncia movilizada. (Fundación Abril, 2005).

${ }^{18}$ El Comité de Defensa del Agua surge a mediados de los años 90. Se dedicaba a discutir y analizar el problema del agua en Cochabamba, sobre todo en lo que respecta al abastecimiento de la población y a la calidad del agua. (Entrevista a Alvarado, 2019). 